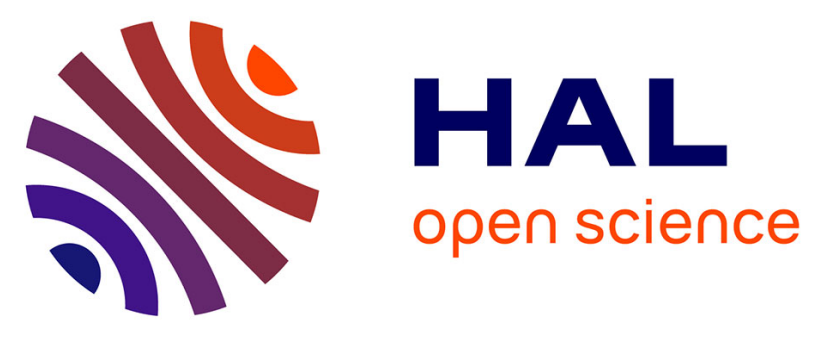

\title{
Evaluation of the environmental contamination and exposure risk in medical/non-medical staff after oxaliplatin-based pressurized intraperitoneal aerosol chemotherapy
}

Marion Larroque, Carine Arnaudguilhem, Brice Bouyssière, François Quenet, Nabila Bouazza, Marta Jarlier, Sonia Boulabas, Sandra Mounicou, Olivia Sgarbura

\section{- To cite this version:}

Marion Larroque, Carine Arnaudguilhem, Brice Bouyssière, François Quenet, Nabila Bouazza, et al.. Evaluation of the environmental contamination and exposure risk in medical/non-medical staff after oxaliplatin-based pressurized intraperitoneal aerosol chemotherapy. Toxicology and Applied Pharmacology, 2021, 429, pp.115694. 10.1016/j.taap.2021.115694 . hal-03335165

\section{HAL Id: hal-03335165}

https: / hal-univ-pau.archives-ouvertes.fr/hal-03335165

Submitted on 25 Nov 2021

HAL is a multi-disciplinary open access archive for the deposit and dissemination of scientific research documents, whether they are published or not. The documents may come from teaching and research institutions in France or abroad, or from public or private research centers.
L'archive ouverte pluridisciplinaire HAL, est destinée au dépôt et à la diffusion de documents scientifiques de niveau recherche, publiés ou non, émanant des établissements d'enseignement et de recherche français ou étrangers, des laboratoires publics ou privés. 


\section{Evaluation of the environmental contamination and exposure risk in medical/non-medical} staff after oxaliplatin-based pressurized intraperitoneal aerosol chemotherapy

1

2 Marion Larroque $^{1, \mathrm{a}, \mathrm{b}, \mathrm{c}}$, Carine Arnaudguilhem ${ }^{1, \mathrm{c}}$, Brice Bouyssiere $^{\mathrm{c}}$, François Quenet ${ }^{\mathrm{b}, \mathrm{f}}$,

3 Nabila Bouazza $^{\mathrm{d}}$, Marta Jarlier ${ }^{\mathrm{e}}$, Sonia Boulabas ${ }^{\mathrm{d}}$, Sandra Mounicou ${ }^{\mathrm{c}}$ and Olivia Sgarbura ${ }^{\mathrm{b}, \mathrm{f}^{*}}$.
5

6

9

10 19

\section{Affiliations}

${ }^{\text {a }}$ Translational Research Unit, Cancer Institute of Montpellier, Montpellier, France

bIRCM, Institut de Recherche en Cancérologie de Montpellier, INSERM U1194, Université de Montpellier, Institut régional du Cancer de Montpellier, Montpellier, F-34298, France.

'University of Pau and Pays de 1'Adour, E2S UPPA, CNRS, Institut des Sciences Analytiques et de Physico-Chimie Pour l'Environnement et les Matériaux (IPREM), UMR5254, Hélioparc, 64053 Pau, France

${ }^{\mathrm{d} S}$ Scientific Direction, ClinicalResearch Center, Cancer Institute of Montpellier, Montpellier, France

${ }^{\mathrm{e} B i o m e t r i c s ~ U n i t, ~ C a n c e r ~ I n s t i t u t e ~ o f ~ M o n t p e l l i e r, ~ M o n t p e l l i e r, ~ F r a n c e ~}$

${ }^{\mathrm{f}}$ Department of Surgical Oncology, Cancer Institute of Montpellier, University of Montpellier, Montpellier, France

${ }^{1}$ These authors had equal contributions to the work

$$
\text { *Corresponding author: }
$$

Olivia SGARBURA, MD, PhD

Department of Surgical Oncology

$$
\text { Cancer Institute of Montpellier }
$$

208, Av. des Apothicaires

5 34298, Montpellier

6 Olivia.sgarbura@icm.unicancer.fr 
Trial registration: NCT04014426

Abstract:

Pressurized intraperitoneal aerosol chemotherapy (PIPAC) is a technique to directly deliver chemotherapeutic drugs in the abdomen for the treatment of peritoneal metastases. Pressurization improves the treatment efficacy but increases the risk of exposure for the medical/non-medical staff who can be contaminated by dermal or ocular contact, or inhalation of aerosols containing the cytotoxic drugs. The aim of this study was to evaluate the risk of contamination for the medical/non-medical staff (nurses, surgeons, anaesthesiologists and cleaning personnel; $\mathrm{n}=13$ ) during PIPAC with oxaliplatin or cisplatin-doxorubicin performed according to the protocol recommended in France. Blood samples were collected 1 hour before and immediately after PIPAC, and urine samples 1 hour before, and then 3 hours and the morning after PIPAC. In the control, non-exposed group $(n=7)$, only one urine and blood sample were collected. Surface contamination in the operating room was assessed in water- and Surfanios-impregnated wipe samples. The total elemental platinum in each sample was quantified by inductively coupled plasma mass spectrometry, using a method adapted to quantify trace amounts $\left(\right.$ ng. $\left.\mathrm{L}^{-1}\right)$ in very low volumes $(100 \mu \mathrm{l})$. No surface contamination was detected. Although $25 \%$ of urine samples in the exposed group contained platinum, no statistical difference was observed in urine and plasma samples collected before and after PIPAC and with the control group samples. These findings suggest that the French PIPAC protocol does not increase the risk of exposure to platinum in all staff categories involved. This protocol could be considered in future occupational policies and consensus statements. 
51 Keywords: PIPAC, oxaliplatin, occupational safety, occupational hazard, personal protective

52

53

54

55

56

57

58

59

60

61

62

63

64

65

66

67

68

69

70

71

72

73

74

75 equipment.

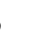

4

\section{Abbreviations}

EG: exposed group

NEG: non-exposed group

PIPAC: pressurized intraperitoneal aerosol chemotherapy

PIPAC-CD: pressurized intraperitoneal aerosol chemotherapy with cisplatin-doxorubicin

PIPAC-Ox: pressurized intraperitoneal aerosol chemotherapy with oxaliplatin

Pt: platinum

2

1. Introduction:

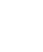

Life-threating peritoneal metastases from various cancers respond poorly to intravenous drugs. Therefore, innovative loco-regional strategies and systemic chemotherapy are currently combined to improve the prognosis of these patients (Ceelen and Flessner, 2010). For instance, pressurized intraperitoneal aerosol chemotherapy (PIPAC) is an intraperitoneal drug delivery method performed in the operating room during laparoscopy (Alyami et al., 2019). Oxaliplatin (PIPAC-Ox) and the cisplatin and doxorubicin combination (PIPAC-CD) are frequently used for PIPAC. PIPAC-Ox is mainly proposed to patients with peritoneal metastases of colorectal origin, but also for other indications (Di Giorgio et al., 2020; Sgarbura et al., 2019). During PIPAC, microdroplets of the chosen chemotherapeutic drug are delivered by constant flow after 4 establishment of a stable pressure capnoperitoneum in the purpose of improving their intraabdominal distribution and penetration in the peritoneal tissue (Solass et al., 2014). PIPAC 
efficacy is based on the delivery of the chemotherapeutic drug(s) in the form of pressurized aerosols during 37 minutes, but this delivery could also increase the risk of exposure to such cytotoxic drugs and represents an occupational hazards for the involved medical/non-medical staff (CDC, n.d.). Specifically, inhalation is considered to be the main contamination route associated with PIPAC, whereas contamination via the dermal and oral routes should be less common. Therefore, in Germany, very rigorous safety protocols have been put in place with at least three containment levels (zero flow abdominal pressure, laminar airflow system in the operating room, and remote controlled administration of the drug) (Solaß et al., 2013). The French safety protocol also includes a plastic sheet around the patient and a toxic gas aspiration device under the sheet during the procedure (Cazauran et al., 2018) as the fourth level of containment. However, a French study suggested that the laminar air flow could be replaced by any advanced airflow system (Delhorme et al., 2019).

Some German groups have already evaluated the occupational exposure risk to platinum linked to PIPAC with platinum-based drugs (Ametsbichler et al., 2018; Solaß et al., 2013). They determined air and surface contamination by quantifying platinum concentration in air and wipe samples, respectively. Operating room air sampling revealed low platinum contamination levels $\left(<9 \mathrm{pg} / \mathrm{m}^{3}\right)$, and surface contamination ranged from 0.01 to $1733 \mathrm{pg} / \mathrm{cm}^{2}$, depending on the area (higher contamination on the injector and trocars) (Ametsbichler et al., 2018). No platinum was detected in the operating room air at the places where the surgeon and anaesthesiologist work during PIPAC (Solaß et al., 2013). These data suggest a low exposure risk when PIPAC is performed following the safety protocol implemented in Germany. Few studies focused on the biological monitoring of the medical staff. In 2016, Graversen et al. showed the absence of contamination in two surgeons after two consecutive PIPAC procedures, by quantifying platinum in blood samples. However, these authors did not describe the method used for platinum quantification and the limits of detection. Ndaw et al. analysed platinum concentration 
101 and did not find any significant difference between groups (Ndaw et al., 2018).

However, to our knowledge, no study measured the platinum concentration in both blood 104

in urine samples of the medical staff collected at $24 \mathrm{~h}$ post-PIPAC-CD and from a control group and urine samples. Moreover, despite this encouraging preliminary evidence and the rigorous safety protocol put in place for the medical (Alyami et al., 2020) and non-medical staff (Al Hosni et al., 2020), the use of PIPAC, and also of other types of intraperitoneal chemotherapy procedures, such as hyperthermic intraperitoneal chemotherapy, is still considered as an occupational hazard and requires continuous updating and education (Al Hosni et al., 2020; Clerc D et al., 2021).

The aim of this study was to evaluate the risk of exposure for the operating room medical/non-medical staff during PIPAC-Ox procedures by measuring and comparing platinum concentration in blood and urine samples collected from potentially exposed staff members and from healthy volunteers. Contamination of the operating room surfaces after PIPAC was also evaluated.

\section{Material and methods:}

\subsection{PIPAC procedure}

The PIPAC procedure is performed in a dedicated operating room with an advanced ventilation system and remote controlled administration according to the French safety protocol (Cazauran et al., 2018). The standardized surgical technique includes a two-port access with double-balloon trocars and aerosolization of the chemotherapeutic drug after evaluation of the metastatic disease, as described elsewhere (Hübner et al., 2017). In PIPAC-Ox, oxaliplatin (92mg. $\left.\mathrm{m}^{-2}\right)$ is diluted in $5 \%$ glucose solution, and administered with a flow of $0.6 \mathrm{ml} . \mathrm{sec}^{-1}$ and 
upstream pressure limit of 290 psi (Dumont et al., 2020; Sgarbura et al., 2020). The total administration time is 37 minutes.

\subsection{Study participants}

The study was carried out at the Cancer Institute of Montpellier (ICM), France, in 2018. In our centre, more than 70 PIPAC procedures are performed annually since its introduction in 2016 (Al Hosni et al., 2020). The operating room staff members who took part in two different PIPAC-Ox sessions two weeks apart were enrolled in the current study: session 1 (one senior surgeon, one assistant surgeon, one circulating nurse, one scrub nurse, one nurse anaesthetist, one anaesthesiologist, and the cleaner), and session 2 (one senior surgeon, one assistant surgeon, one circulating nurse, one scrub nurse, one nurse anaesthetist, one anaesthesiologist). With the exception of the anaesthesiologists and of the senior surgeon, all staff members involved in PIPAC delivery undergo a 2-week non-exposure period before and between PIPAC sessions. The participation was voluntary and the group was defined as "Exposed group" (EG). Seven healthy volunteers formed the control "Non-Exposed group" (NEG) and were selected among the ICM researchers and administrative staff who had no identified contact with platinum-containing cytotoxic drugs.

All participants received oral and written information about the study and signed an informed consent. The study was carried out in accordance with the current version of the Declaration of Helsinki and approved by a national ethics committee (2017-A01921-52). The study was registered at ClinicalTrials.gov (NCT04014426).

\subsection{Analysis of biological samples}

In the EG group, blood samples were collected in heparinized tubes 1hour before and immediately after the PIPAC intervention. Urine samples were collected 1 hour before (T0), 3 
150

151

152

153

154

155

156

157

hours after (T1), and the morning (T2) after the PIPAC procedure. In the NEG group, only one sample of urine and one sample of plasma were collected. Plasma was separated from blood by centrifugation at $2000 \mathrm{~g}$ for 5 minutes. All biological samples were stored at $-80^{\circ} \mathrm{C}$ until analysis.

Several methods using mineralization or direct dilution in acidic or alkaline media were previously published for platinum quantification in biological samples (Abduljabbar et al., 2019; Chantada-Vázquez et al., 2019; Gong et al., 2017; Lu et al., 2015). Nevertheless, due to the very small concentrations (ng. $\mathrm{L}^{-1}$ ) and small sample volume, these methods could not be used directly. Therefore, the method was optimized using oxaliplatin-spiked samples. Briefly, mineralization was optimized in acidic $\left(69 \% \mathrm{HNO}_{3} / \mathrm{H}_{2} \mathrm{O}_{2}\right)$ or alkaline (25\% tetramethyl ammonium hydroxide, TMAH) solutions at different ratios, but important matrix effect and nebulization clogging was observed. A 5- or 10-fold dilution in nitric acid did not improve platinum recovery as protein precipitation leads to the loss of platinum. Finally, a direct 10-fold dilution in $0.1 \%$ TMAH/ $0.1 \%$ Triton $\mathrm{X}-100$ was retained to minimize the matrix effect, with a $>75 \%$ recovery.

Thus, a $100 \mu \mathrm{L}$ aliquot of each plasma and urine sample was 10 -fold diluted in $0.1 \%$ TMAH/0.1\% Triton X-100 (Sigma Aldrich, St Quentin Falavier, France). Tantalum (PlasmaCAL, SCP Science, Courtaboeuf, France) was added at a concentration of 1 ng.L $\mathrm{L}^{-1}$ as internal standard. After stirring, samples were centrifuged at $11000 \mathrm{rpm}, 4^{\circ} \mathrm{C}$ for $15 \mathrm{~min}$, and analysed by Inductively Coupled Plasma Mass Spectrometry (ICP-MS). Matrix-dependent calibration curves were obtained by spiking known concentrations of pure oxaliplatin in the control urine or plasma samples to study the matrix effect. Then, the limit of detection (LOD) and of quantification (LOQ) were estimated as 3 and 10 times, respectively, the standard deviation of the intercept divided by the calibration curve slope. 

quantification $(L O Q)$.

\subsubsection{Standardization and LOQ determination:}

An oxaliplatin standard solution (platinum concentration ranging from $70 \mathrm{fg} . \mathrm{cm}^{-2}$ to 250 ng.cm ${ }^{-2}$ ), water, or the surface disinfectant Surfanios (blanks) were deposited onto $4 \mathrm{~cm}^{2}$ glass surfaces and allowed to dry under moderate heating $\left(50^{\circ} \mathrm{C}\right)$. After complete dryness, each surface was rubbed with a $2.25 \mathrm{~cm}^{2}$ multi-layered wipe wetted with $150 \mu \mathrm{l}$ of water or Surfanios. Wipes were then mineralized by addition of $400 \mu 1$ pure nitric acid and $150 \mu 1$ of hydrogen peroxide (Sigma Aldrich, St Louis Missouri, United States) at $75^{\circ} \mathrm{C}$ for 3 hours, and centrifuged at $15000 \mathrm{~g}$ for $15 \mathrm{~min}$. Platinum in the supernatant was then quantified by ICP-MS after addition of $1 \mu \mathrm{g} . \mathrm{L}^{-1}$ indium as internal standard (SCP Science, Courtaboeuf, France). The LOQ after recovery was determined as the lowest concentration that can be measured with an accuracy within $30 \%$ of the nominal value deposited onto the test surface.

\subsubsection{Operating room surface contamination:}

Six potentially contaminated surfaces were identified on the basis of previous publications and the operating room staff's experience: anaesthesia monitoring screen, surgical lamp, laparoscopy tower, surgical gas aspirator, surgical gas aspiration filter, and laparoscopic monitor (Fig. 1). To evaluate their contamination, surfaces $\left(\right.$ area $=9 \mathrm{~cm}^{2}$ ) were rubbed twice with water- or Surfanios-impregnated multi-layered wipes in both directions by the same experienced person who collected the wipe samples also for the standardization experiment. Wipes were handled as described in 2.4.1 and platinum quantified by ICP-MS.

\subsection{Analytical quantification}

Diluted serum and urine samples were analysed using an Agilent 7700x quadrupole ICPMS (Agilent Technologies, Tokyo, Japan) equipped with a Scott spray chamber (cooled at $2{ }^{\circ} \mathrm{C}$ ), 
a MicroMist nebulizer $\left(400 \mu \mathrm{L} \cdot \mathrm{min}^{-1}\right), \mathrm{X}$-Lenses and nickel cones. Plasma power was set to 201 1550W. Platinum determination was performed by quantifying three major isotopes $\left({ }^{194} \mathrm{Pt}\right.$, ${ }^{195} \mathrm{Pt},{ }^{196} \mathrm{Pt}$ ) with an integration time of $999 \mathrm{msec}$ per isotope. Quantification was performed by internal calibration with tantalum-181 (integration time 100ms).

After acid digestion, wipes were analysed by high resolution ICP-MS using an Element XR (ThermoScientific, Bremen, Germany) equipped with a Scott spray chamber (cooled at $2^{\circ} \mathrm{C}$ ), a

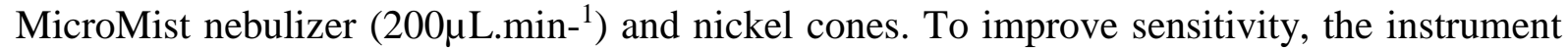
operating conditions were plasma power of $1200 \mathrm{~W}$ and low resolution $(\mathrm{m} / \Delta \mathrm{m} 400)$. Internal calibration was performed for platinum quantification using indium as internal standard. ${ }^{194} \mathrm{Pt}$, ${ }^{195} \mathrm{Pt}$ and ${ }^{115}$ In were monitored (50 sample/peak, mass window $20 \%$, sample time 5 sec for ${ }^{194} \mathrm{Pt}$ and ${ }^{195} \mathrm{Pt}$ and $10 \mathrm{msec}$ for ${ }^{115} \mathrm{In}$ ). Platinum concentrations were determined using the ${ }^{194} \mathrm{Pt}$ and ${ }^{195} \mathrm{Pt}$ values, but only the ${ }^{195} \mathrm{Pt}$ concentration was reported, if not otherwise mentioned. All standard solutions were from SCP Science (Courtaboeuf, France).

\subsection{Statistical analysis}

The descriptive analysis was performed using median and range for continuous parameters, frequency and percentage for categorical variables. The comparative analysis was based on non-parametric tests (Mann Whitney, Wilcoxon) and was performed with STATA 16 (Stata Corporation, College Station, Tx, USA). A p-value $<0.05$ was considered significant.

\section{Results}

\subsection{Platinum concentration in biological samples}


The instrument LOD and LOQ of platinum were estimated at 0.3 ng. $\mathrm{L}^{-1}$ and 0.9 ng. $\mathrm{L}^{-1}$ 224 respectively. This corresponded to 5 and 16 ng.L $\mathrm{L}^{-1}$, respectively, in plasma, and to 3 and 9 ng.L-

225 , respectively, in urine, by taking into account the matrix effect and dilution factor.

226 In the EG, 37 urine samples were collected from 13 medical/non-medical staff members 227 implicated in the two PIPAC procedures (Table 1). Before PIPAC (T0), platinum concentration 228 was below the LOQ in $9 / 13$ urine samples $(69 \%)$, and could not be detected $(<$ LOD) in $7 / 13$ 229 samples (54\%). Only 4/13 samples (31\%) contained platinum (from 9.8 to 42 ng.L $\mathrm{L}^{-1}$ ). After 230 PIPAC, platinum concentration in urine samples was below the LOQ in 18/24 samples (75\%) $231(18 / 24)$ and remained undetectable in 10/24 samples (42\%). Platinum could be quantified in $2326 / 24$ urine samples $(25 \%)$ and the concentration ranged from 12.5 to $367 \mathrm{ng} . \mathrm{L}^{-1}$. The two 233 anaesthesiologists' and the senior surgeon's urine samples at T0 were positive (4 and 11). One 234 surgeon, one assistant surgeon, one circulating nurse and one scrub nurse had positive urine 235 samples at T2. In all plasma samples, platinum concentration was below the LOQ $(7 / 25 ; 28 \%)$ or the LOD $(18 / 25 ; 72 \%)$ before and also after PIPAC.

There was no statistical difference in platinum concentration in urine and plasma samples collected before and after PIPAC $(\mathrm{p}=0.2)$.

239 In the NEG $(n=7)$, all plasma samples were below the LOQ, and platinum could not be detected (<LOD) in 6/7 samples (86\%). Conversely, in two urine samples, platinum concentration was slightly above the LOQ and in two slightly below the LOD. There was no

242 statistical difference in the platinum concentrations in the EG and NEG urine and plasma 243 samples $(\mathrm{p}=0.2)$.

\subsection{Surface contamination}

Water- and Surfanios-impregnated wipes with known concentrations of oxaliplatin (from $24770 \mathrm{fg} \cdot \mathrm{cm}^{-2}$ to $250 \mathrm{ng} \cdot \mathrm{cm}^{-2}$ ) were used to determine the platinum recovery yield that was higher 
with water-impregnated wipes (Fig. 2). The LOQ with water-impregnated wipes was 2.5 pg.cm

251 surfaces.

\section{Discussion:}

The current study shows that exposure to oxaliplatin during PIPAC-Ox performed following the current French safety protocol is non-existent for all the involved medical/nonmedical staff members. This is the first study to extensively investigate PIPAC-Ox occupational exposure risk by analysing both environmental and biological samples.

PIPAC-Ox was initially used for colorectal cancer peritoneal metastases (Demtröder et al., 2016), and was then enlarged to other types of gastrointestinal cancers (Di Giorgio et al., 2020; Sgarbura et al., 2019). Although there is no report on the exact number of healthcare centres performing PIPAC-Ox worldwide, the recently published PIPAC survey identified 62 centres that carried out at least 5972 procedures in 20 countries, and $74 \%$ of all respondents 263 confirmed the use of oxaliplatin (Sgarbura et al., 2020). However, studies on PIPAC-Ox-linked 264 surface and biological contamination are scarce (Graversen et al., 2016) and based on limited data. The findings of the current study confirm that PIPAC-Ox use in the operating room following specific protection regulations (i.e. the French safety protocol) does not increase the risk of exposure to platinum compared with controls. Moreover, platinum concentration in all 268 environmental samples was below the LOQ, although previous studies identified the injector 269 surface as a safety hazard (Ametsbichler et al., 2018; Ndaw et al., 2018). The results of the present study are based on the analysis of two different biological 271 samples (urine and blood) and environmental samples. Moreover, before the analysis of 272 environmental samples, the recovery yield was evaluated by ICP-MS quantification of the 
273 platinum concentration in water- or Surfanios-impregnated wipes that were used to clean 274 surfaces with a known oxaliplatin concentration. In previous studies, only the extraction 275 (mineralization, liquid extraction) and/or quantification methods were evaluated (Ndaw et al., 276 2018). A better sensitivity was obtained with water-impregnated wipes. Platinum 277 concentrations of the operating room samples after PIPAC were all below the LOQ. As we 278 assumed a recover yield above $70 \%$ from the surface to the test tube, we considered that the 279 operating room was not contaminated after the PIPAC procedure.

281 blood and/or urine samples based on the known pharmacokinetic properties of oxaliplatin 282 (Graham et al, 2000; Ceelen and Flessner, 2010; Villa et al, 2015; Ndaw et al, 2018). Our 283 analytical method gave LOD and LOQ for urine and blood samples that are within the 284 previously published ranges. Urinary platinum concentration is commonly used to evaluate contamination by platinum salts because platinum is rapidly cleared from the plasma, and urinary excretion is considered the predominant route of elimination (Graham et al., 2000). As previous studies used 24h urine samples (Konate et al., 2011) or pre-shift and post-shift urine samples (Ndaw et al., 2018), we cannot directly compare our results (1 hour before, 3 hours 289 after, and the morning after the PIPAC procedure). We chose this sampling schedule on the basis of pharmacokinetic data obtained after intravenous injection of oxaliplatin that showed a concentration decreases by $50 \%$ at 6 h post-injection (Graham et al., 2000). After PIPAC, 25\%

292 of urine samples in the EG were positive. However, the urine samples of the anaesthesiologists 293 and of the senior surgeon were positive already at T0. These staff members did not have a 2294 week non-exposure period before and between PIPAC procedures. That is not the case for the 295 scrub nurse of the second procedure where urine sample was also positive at T0 without any 296 identified exposure. The other positive samples at T2 were from the surgeon, assistant surgeon, 297 circulating nurse, and scrub nurse implicated in the second PIPAC session. However, these 
results (platinum ranging from 10.5 to $367 \mathrm{ng} . \mathrm{L}^{-1}$ ) are in the same range but cannot be directly compared with the maximum concentration of $136 \mathrm{ng} . \mathrm{L}^{-1}$ detected in $24 \mathrm{~h}$ urine collected after PIPAC (Ndaw et al., 2018), or the 1300 ng. $\mathrm{L}^{-1}$ in post-shift urine samples from nurses or pharmacy technicians (Turci et al., 2002). Furthermore, no statistical difference was observed for urine samples collected before and after PIPAC and between EG and NEG samples, strongly suggesting that the level of contamination in urine is not significant.

As oxaliplatin binds to plasma proteins (Casini and Reedijk, 2012; Chalret du Rieu et al., 2014; Turci et al., 2002), we analysed also blood samples collected before and after PIPAC. Several methods using mineralization or direct dilution in acidic or alkaline media were previously described (Abduljabbar et al., 2019; Chantada-Vázquez et al., 2019; Gong et al., 2017; Lu et al., 2015). Nevertheless, due to the very small concentrations of platinum (ng. $\left.\mathrm{L}^{-1}\right)$ and the small sample volume, these methods could not be used directly. Therefore, we optimized them using oxaliplatin-spiked samples and we chose a direct 10 -fold dilution in $0.1 \%$ TMAH/0.1\% Triton X100 to minimize the matrix effect compared with mineralization in $\mathrm{HNO}_{3}$ or TMAH alone. Indeed, the combination of TMAH, which improves protein solubilization by cutting protein disulphide bridges, and Triton X-100, which improves cell lysing, protein and fat solubilization, allowed us to efficiently recover platinum from plasma and urine. For all plasma samples, the platinum concentration never exceeded the LOQ, without any significant difference between pre- and pots-PIPAC values and with the NEG. These results indicate the effectiveness of the implemented PIPAC safety protocol.

It would be now important to review all the available evidence concerning PIPAC safety for the involved medical/non-medical staff to define international guidelines. These recommendations could then be considered as the expert opinion to be taken into account by regulatory bodies to define a homogenous safety protocol for PIPAC procedures worldwide. 
323 and the fact that the included staff members have been repeatedly exposed to oxaliplatin.

324 Moreover, the number of samples collected from each participant was limited in time (before,

325 after and the morning after PIPAC). The current findings cannot be extended to ePIPAC that 326 has administration times shorter than 30 minutes (Taibi et al., 2020) because in this case the 327 operating room staff return in the room earlier after the remote administration, and this might 328 modify the risk of exposure.

In conclusion, PIPAC-Ox performed following the French safety protocol does not seem

to increase the risk of platinum exposure for the involved medical/non-medical staff. Therefore,

this safety protocol could be considered in future occupational policies and consensus statements.

Funding: Aquitaine Region and Feder are acknowledged for the funding of the LA-ICP MS system under the AQUITRACE project (convention number 20131206001-13010973).SIRIC of the project.

\section{References}

Abduljabbar, T.N., Sharp, B.L., Reid, H.J., Barzegar-Befroeid, N., Peto, T., Lengyel, I., 2019. Determination of $\mathrm{Zn}, \mathrm{Cu}$ and $\mathrm{Fe}$ in human patients' serum using micro-sampling ICPMS and sample dilution. Talanta 204, 663-669. https://doi.org/10.1016/j.talanta.2019.05.098

Al Hosni, M., Rouget, C., Cusumano, C., GarciaLozcano, E., Popescu, H., Carrere, S., Quénet, F., Sgarbura, O., 2020. Non-medical caregivers and the use of intraperitoneal chemotherapy in the operating theatre: A survey on the perception of safety. Journal of Visceral Surgery. https://doi.org/10.1016/j.jviscsurg.2020.02.005 
Alyami, M., Hübner, M., Grass, F., Bakrin, N., Villeneuve, L., Laplace, N., Passot, G., Glehen, O., Kepenekian, V., 2019. Pressurised intraperitoneal aerosol chemotherapy: rationale, evidence, and potential indications. The Lancet Oncology 20, e368-e377. https://doi.org/10.1016/S1470-2045(19)30318-3

Alyami, M., Sgarbura, O., Khomyakov, V., Horvath, P., Vizzielli, G., So, J., Torrent, J., Delgadillo, X., Martin, D., Ceelen, W., Reymond, M., Pocard, M., Hübner, M., 2020. Standardizing training for Pressurized Intraperitoneal Aerosol Chemotherapy. European Journal of Surgical Oncology. https://doi.org/10.1016/j.ejso.2020.05.007

Ametsbichler, P., Böhlandt, A., Nowak, D., Schierl, R., 2018. Occupational exposure to cisplatin/oxaliplatin during Pressurized Intraperitoneal Aerosol Chemotherapy (PIPAC)? European Journal of Surgical Oncology 44, 1793-1799. https://doi.org/10.1016/j.ejso.2018.05.020

Casini, A., Reedijk, J., 2012. Interactions of anticancer Pt compounds with proteins: an overlooked topic in medicinal inorganic chemistry? Chemical Science 3, 3135. https://doi.org/10.1039/c2sc20627g

Cazauran, J.-B., Alyami, M., Lasseur, A., Gybels, I., Glehen, O., Bakrin, N., 2018. Pressurized Intraperitoneal Aerosol Chemotherapy (PIPAC) Procedure for Nonresectable Peritoneal Carcinomatosis (with Video). Journal of Gastrointestinal Surgery 22, 374-375. https://doi.org/10.1007/s11605-017-3565-0

CDC, n.d. NIOSH [WWW Document]. URL https://www.cdc.gov/niosh/

Ceelen, W.P., Flessner, M.F., 2010. Intraperitoneal therapy for peritoneal tumors: biophysics and clinical evidence. Nature Reviews Clinical Oncology 7, 108-115. https://doi.org/10.1038/nrclinonc.2009.217

Chalret du Rieu, Q., White-Koning, M., Picaud, L., Lochon, I., Marsili, S., Gladieff, L., Chatelut, E., Ferron, G., 2014. Population pharmacokinetics of peritoneal, plasma ultrafiltrated and protein-bound oxaliplatin concentrations in patients with disseminated peritoneal cancer after intraperitoneal hyperthermic chemoperfusion of oxaliplatin following cytoreductive surgery: Cancer Chemotherapy and Pharmacology 74, 571-582. https://doi.org/10.1007/s00280-014-2525-6

Chantada-Vázquez, M.P., Herbello-Hermelo, P., Bermejo-Barrera, P., Moreda-Piñeiro, A., 2019. Discrete sampling based-flow injection as an introduction system in ICP-MS for the direct analysis of low volume human serum samples. Talanta. https://doi.org/10.1016/j.talanta.2019.02.050

Clerc, D., Hübner, M., Ashwin, K.R., Somashekhar, S.P., Rau, B., Ceelen, W., Willaert, W., Bakrin, N., Laplace, N., Al Hosni, M., Garcia Lozcano, E.L., Blaj, S., Piso, P., Di Giorgio, A., Vizzelli, G., Brigand, C., Delhorme, J.B., Klipfel, A., Archid, R., Nadiradze, G., Reymond, M.A., Sgarbura, O. Current practice and perceptions of safety protocols for the use of intraperitoneal chemotherapy in the operating room: results of the IP-OR international survey. Pleura and Peritoneum. vol. 6, no. 1, 2021, pp. 39-45. https://doi.org/10.1515/pp-2020-0148

Delhorme, J.B., Klipfel, A., D’Antonio, F., Greget, M.C., Diemunsch, P., Rohr, S., Romain, B., Brigand, C., 2019. Occupational safety of pressurized intraperitoneal aerosol chemotherapy (PIPAC) in an operating room without laminar airflow. Journal of Visceral Surgery. https://doi.org/10.1016/j.jviscsurg.2019.06.010

Demtröder, C., Solass, W., Zieren, J., Strumberg, D., Giger-Pabst, U., Reymond, M.A., 2016. Pressurized intraperitoneal aerosol chemotherapy with oxaliplatin in colorectal peritoneal metastasis. ColorectalDisease. https://doi.org/10.1111/codi.13130

Di Giorgio, A., Sgarbura, O., Rotolo, S., Schena, C.A., Bagalà, C., Inzani, F., Russo, A., Chiantera, V., Pacelli, F., 2020. Pressurized intraperitoneal aerosol chemotherapy with cisplatin and doxorubicin or oxaliplatin for peritoneal metastasis from pancreatic 
adenocarcinoma and cholangiocarcinoma. Therapeutic Advances in Medical Oncology. https://doi.org/10.1177/1758835920940887

Dumont, F., Passot, C., Raoul, J.-L., Kepenekian, V., Lelièvre, B., Boisdron-Celle, M., Hiret, S., Senellart, H., Pein, F., Blanc-Lapierre, A., Raimbourg, J., Thibaudeau, E., Glehen, O., 2020. A phase I dose-escalation study of oxaliplatin delivered via a laparoscopic approach using pressurised intraperitoneal aerosol chemotherapy for advanced peritoneal metastases of gastrointestinal tract cancers. European Journal of Cancer 140, 37-44. https://doi.org/10.1016/j.ejca.2020.09.010

Gong, Z.S., Jiang, X.H., Sun, C.Q., Tian, Y.P., Guo, G.H., Zhang, Y.Z., Zhao, X.H., Wang, Y., 2017. Determination of 21 elements in human serum using ICP-MS with collision/reaction cell. International Journal of Mass Spectrometry. https://doi.org/10.1016/j.ijms.2017.10.001

Graham, M.A., Lockwood, G.F., Greenslade, D., Brienza, S., Bayssas, M., Gamelin, E., 2000. Clinical pharmacokinetics of oxaliplatin: A critical review. Clinical Cancer Research.

Graversen, M., Pedersen, P.B., Mortensen, M.B., 2016. Environmental safety during the administration of Pressurized IntraPeritoneal Aerosol Chemotherapy (PIPAC). Pleura and Peritoneum 1. https://doi.org/10.1515/pp-2016-0019

Hübner, M., Grass, F., Teixeira-Farinha, H., Pache, B., Mathevet, P., Demartines, N., 2017. Pressurized IntraPeritoneal Aerosol Chemotherapy - Practical aspects. European Journal of Surgical Oncology (EJSO) 43, 1102-1109. https://doi.org/10.1016/j.ejso.2017.03.019

Konate, A., Poupon, J., Villa, A., Garnier, R., Hasni-Pichard, H., Mezzaroba, D., Fernandez, G., Pocard, M., 2011. Evaluation of environmental contamination by platinum and exposure risks for healthcare workers during a heated intraperitoneal perioperative chemotherapy (HIPEC) procedure. Journal of Surgical Oncology 103, 6-9. https://doi.org/10.1002/jso.21740

Lu, Y., Kippler, M., Harari, F., Grandér, M., Palm, B., Nordqvist, H., Vahter, M., 2015. Alkali dilution of blood samples for high throughput ICP-MS analysis - comparison with acid digestion. Clinical Biochemistry 48, 140-147. https://doi.org/10.1016/j.clinbiochem.2014.12.003

Ndaw, S., Hanser, O., Kenepekian, V., Vidal, M., Melczer, M., Remy, A., Robert, A., Bakrin, N., 2018. Occupational exposure to platinum drugs during intraperitoneal chemotherapy. Biomonitoring and surface contamination. Toxicology Letters 298, 171-176. https://doi.org/10.1016/j.toxlet.2018.05.031

Sgarbura, O., Hubner, M., Alyami, M., Eveno, C., Gagnière, J., Pache, B., Pocard, M., Glehen, O., Quénet, F., 2019. Oxaliplatin use in pressurized intraperitoneal aerosole chemotherapy(PIPAC) is safe and well tolerated: a multicenter study. European Journal of Surgical Oncology 45, e60. https://doi.org/10.1016/j.ejso.2018.10.226

Sgarbura, O., Villeneuve, L., Alyami, M., Bakrin, N., Torrent, J.J., Eveno, C., Hübner, M., PIPAC study group, I., Ceelen, W., 2020. Current practice of pressurized intraperitoneal aerosol chemotherapy (PIPAC) : still standardized or on the verge of diversification? EUROPEAN JOURNAL OF SURGICAL ONCOLOGY. https://doi.org/10.1016/j.ejso.2020.08.020

Solaß, W., Giger-Pabst, U., Zieren, J., Reymond, M.A., 2013. Pressurized Intraperitoneal Aerosol Chemotherapy (PIPAC): Occupational Health and Safety Aspects. Ann Surg Oncol 20, 3504-3511. https://doi.org/10.1245/s10434-013-3039-X

Solass, W., Kerb, R., Mürdter, T., Giger-Pabst, U., Strumberg, D., Tempfer, C., Zieren, J., Schwab, M., Reymond, M.A., 2014. Intraperitoneal Chemotherapy of Peritoneal Carcinomatosis Using Pressurized Aerosol as an Alternative to Liquid Solution: First 
Evidence for Efficacy. Annals of Surgical Oncology 21, 553-559. https://doi.org/10.1245/s10434-013-3213-1

Taibi, A., Teixeira Farinha, H., Durand Fontanier, S., Sayedalamin, Z., Hübner, M., Sgarbura, O., 2020. Pressurized Intraperitoneal Aerosol Chemotherapy Enhanced by Electrostatic Precipitation (ePIPAC) for Patients with Peritoneal Metastases. Ann SurgOncol. https://doi.org/10.1245/s10434-020-09332-6

Turci, R., Sottani, C., Ronchi, A., Minoia, C., 2002. Biological monitoring of hospital personnel occupationally exposed to antineoplastic agents. ToxicolLett 134, 57-64. https://doi.org/10.1016/s0378-4274(02)00163-7

Villa, A.F., El Balkhi, S., Aboura, R., Sageot, H., Hasni-Pichard, H., Pocard, M., Elias, D., Joly, N., Payen, D., Blot, F., Poupon, J., Garnier, R. Evaluation of oxaliplatin exposure of healthcare workers during heated intraperitoneal perioperative chemotherapy (HIPEC). nd Health. 2015;53(1):28-37. doi: 10.2486/indhealth.2014-0025.

\section{Larroque et al Figure 1}

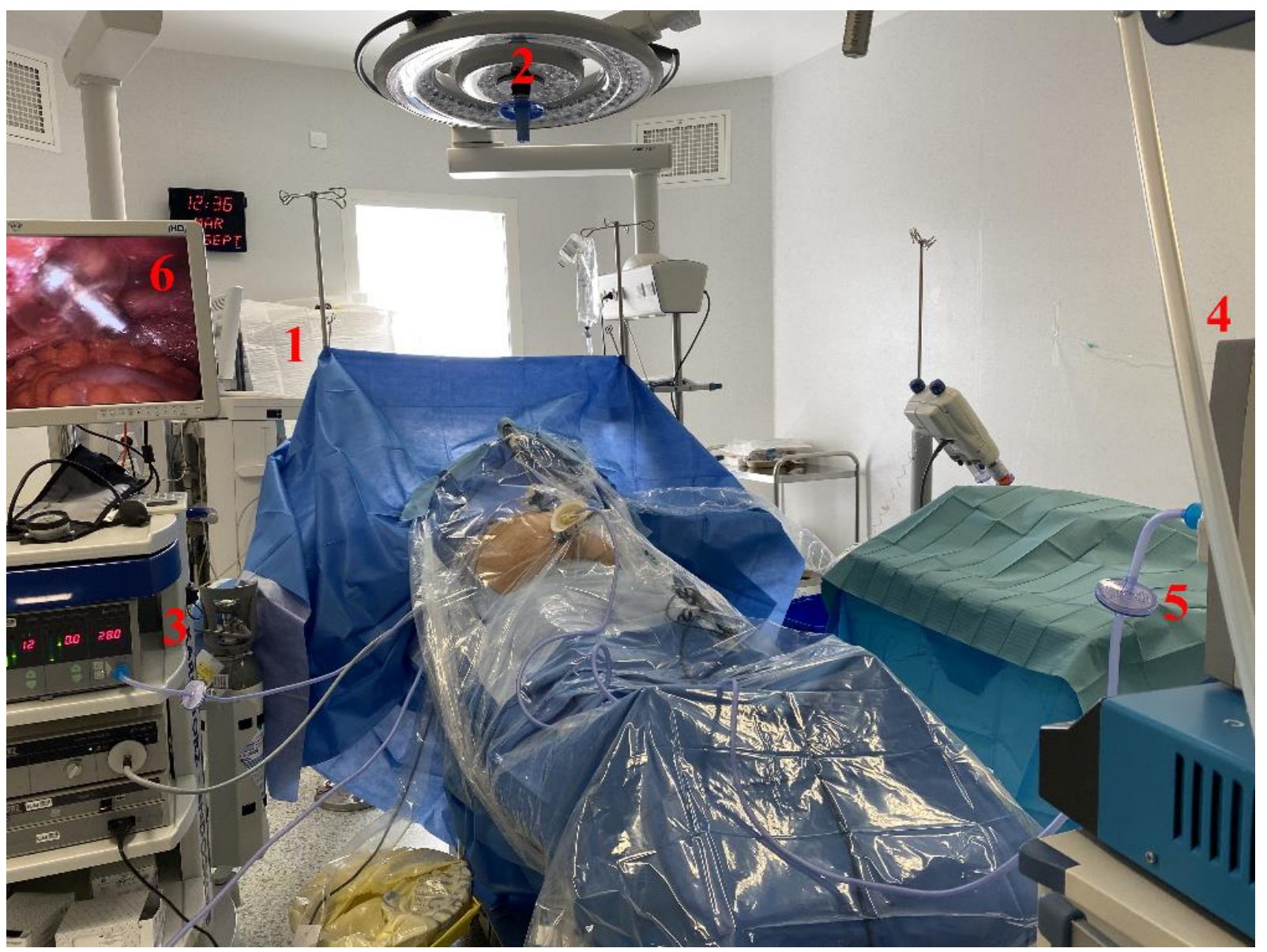

Figure 1: Sampling areas in the operating room: monitoring screen (1), surgical lamp (2), laparoscopy tower (3), surgical-gas aspiring device console (4), surgical gas aspiration filter (5), and laparoscopic monitor (6). 


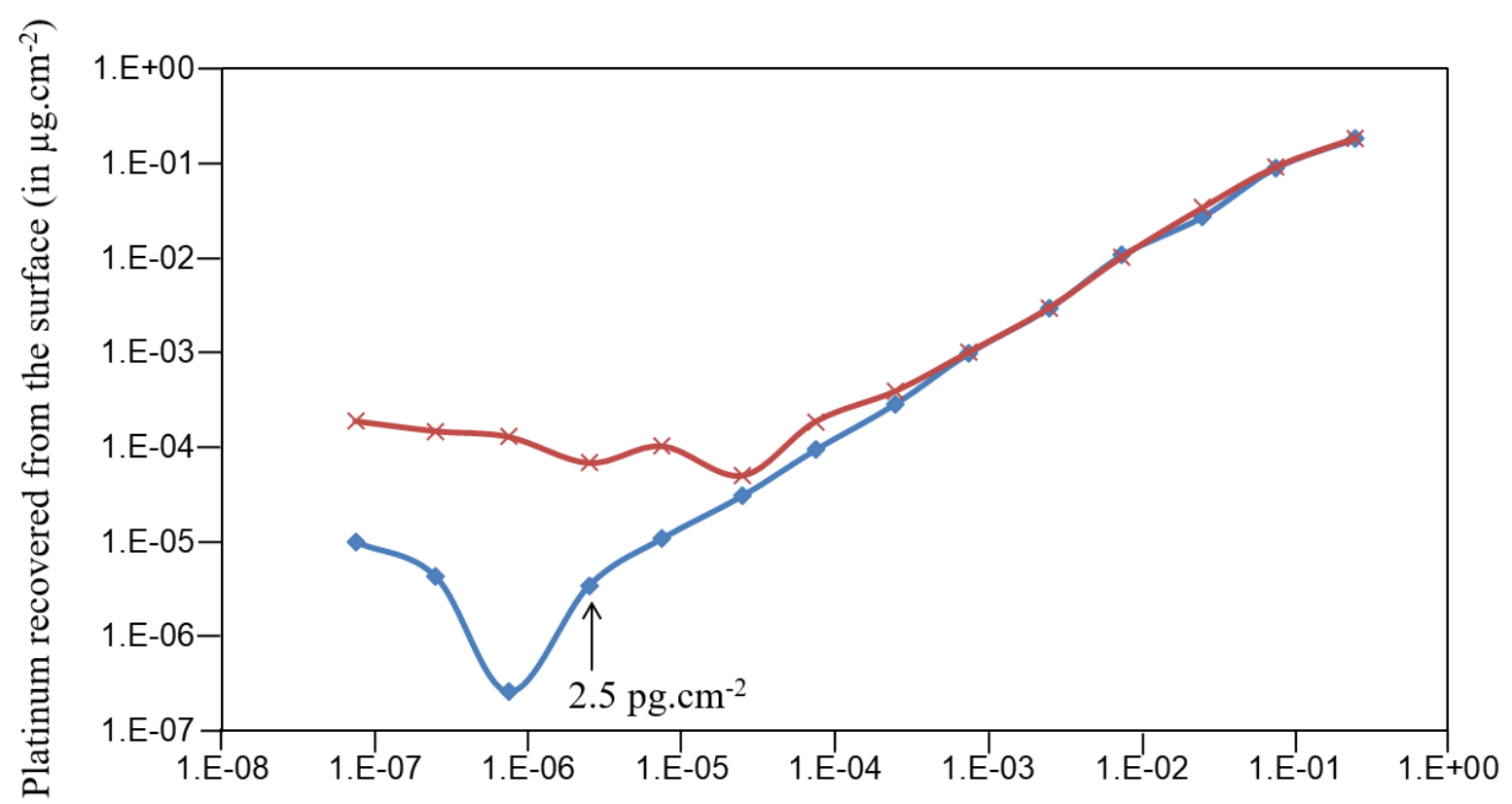

Platinum amount deposited onto the surface (in $\mu \mathrm{g} . \mathrm{cm}^{-2}$ )

474 Figure 2: Determination of the platinum recovered from water- ( - ) or Surfanios- (x)

475 impregnated wipes used to wipe test surfaces contaminated with known platinum

476 concentrations ranging from $100 \mathrm{fg} \cdot \mathrm{cm}^{-2}$ to $1 \mu \mathrm{g} \cdot \mathrm{cm}^{-2}$. 


\begin{tabular}{|c|c|c|c|c|c|c|}
\hline & \multirow[t]{2}{*}{ Participant } & \multicolumn{3}{|c|}{$\begin{array}{c}\text { Pt concentration in urine } \\
\left(n g . L^{-1}\right)\end{array}$} & \multicolumn{2}{|c|}{ Pt Concentration in plasma $\left(\right.$ ng. $\left.\mathrm{L}^{-1}\right)$} \\
\hline \multirow{14}{*}{$\begin{array}{l}\text { Exposed } \\
\text { group }\end{array}$} & & TO & $\mathbf{T 1}$ & $\mathbf{T} 2$ & T0 & T1 \\
\hline & 1 & $<$ LOD & $<\mathrm{LOQ}$ & $<\mathrm{LOQ}$ & $<$ LOD & $<\mathrm{LOQ}$ \\
\hline & 2 & $<\mathrm{LOQ}$ & $<$ LOQ & $<\mathrm{LOQ}$ & $<\mathrm{LOD}$ & $<\mathrm{LOD}$ \\
\hline & 3 & $<$ LOD & $<$ LOD & $<$ LOD & $<$ LOQ & $<\mathrm{LOD}$ \\
\hline & 4 & 10 & $<\mathrm{LOQ}$ & $<$ LOD & $<$ LOD & $<\mathrm{LOD}$ \\
\hline & 5 & $<$ LOD & $<\mathrm{LOQ}$ & $<$ LOD & $<$ LOD & $<\mathrm{LOD}$ \\
\hline & 6 & $<\mathrm{LOD}$ & $<\mathrm{LOD}$ & $<\mathrm{LOD}$ & $<\mathrm{LOD}$ & $<$ LOD \\
\hline & 7 & $<\mathrm{LOQ}$ & $<\mathrm{LOD}$ & & $<\mathrm{LOQ}$ & \\
\hline & 8 & $<$ LOD & $<$ LOQ & 367 & $<\mathrm{LOD}$ & $<\mathrm{LOD}$ \\
\hline & 9 & 42 & $<\mathrm{LOD}$ & 113 & $<\mathrm{LOD}$ & $<\mathrm{LOD}$ \\
\hline & 10 & $<\mathrm{LOD}$ & $<\mathrm{LOD}$ & 13.9 & $<\mathrm{LOD}$ & $<\mathrm{LOQ}$ \\
\hline & 11 & $<\mathrm{LOD}$ & 12.5 & $<\mathrm{LOD}$ & $<\mathrm{LOD}$ & $<\mathrm{LOQ}$ \\
\hline & 12 & 13.8 & 19.2 & $<\mathrm{LOQ}$ & $<\mathrm{LOD}$ & $<\mathrm{LOQ}$ \\
\hline & 13 & 9.8 & & 49.6 & $<\mathrm{LOD}$ & $<\mathrm{LOQ}$ \\
\hline \multirow{7}{*}{$\begin{array}{l}\text { Non exposed } \\
\text { group }\end{array}$} & 14 & $<\mathrm{LOQ}$ & & & $<\mathrm{LOD}$ & \\
\hline & 15 & $<$ LOD & & & $<$ LOD & \\
\hline & 16 & $<\mathrm{LOQ}$ & & & $<$ LOD & \\
\hline & 17 & $<\mathrm{LOD}$ & & & $<\mathrm{LOQ}$ & \\
\hline & 18 & $<\mathrm{LOQ}$ & & & $<\mathrm{LOD}$ & \\
\hline & 19 & 9.7 & & & $<$ LOD & \\
\hline & 20 & 11 & & & $<$ LOD & \\
\hline
\end{tabular}

Table 1. Elemental platinum concentration $\left(n g . \mathrm{L}^{-1}\right)$ in plasma and in urine of participants from the exposed and non-exposed groups. LOD (urine) $=3 \mathrm{ng} . \mathrm{L}^{-1} ; \mathrm{LOQ}$ (urine) $=9 \mathrm{ng} . \mathrm{L}^{-1}$; LOD (plasma) $=5$ ng. $\mathrm{L}^{-1} ; \mathrm{LOQ}$ (plasma) $=16 \mathrm{ng} . \mathrm{L}^{-1}$. In the Exposed group: participants 1 to 7 were involved in the first PIPAC session, and participants 8 to 13 in the second, as follows: 1 (senior surgeon), 2 (assistant surgeon), 3 (circulating nurse), 4 (anaesthesiologist), 5 (nurse anaesthetist), 6 (scrub nurse), 7 (cleaner), 8 (assistant surgeon), 9 (senior surgeon), 10 (circulating nurse), 11 (nurse anaesthetist), 12 (anaesthesiologist), and 13 (scrub nurse). 